"This is the peer reviewed version of the following article: Chem. Eur. J. 2016, 22, 1722-1727, which has been published in final form at DOI: $10.1002 /$ chem.201504510. This article may be used for non-commercial purposes in accordance with Wiley Terms and Conditions for Self-Archiving published at http://olabout.wiley.com/WileyCDA/Section/id-820227.html." 


\title{
Stereodivergent Carbamate Synthesis by Selective In Situ Trapping of Organic Carbonate Intermediates
}

\author{
Wusheng Guo, ${ }^{[a][b]}$ Victor Laserna, ${ }^{[a][b]}$ Eddy Martin, ${ }^{[a]}$ Eduardo C. Escudero-Adán ${ }^{[a]}$ and Arjan W. \\ Kleij ${ }^{*[a][c]}$
}

\begin{abstract}
Trans-carbamate structures can be prepared in a diastereoselective approach by a judicious one-pot combination of in situ prepared organic carbonates and suitable amine reagents under appropriate reaction conditions. This unprecedented approach allows for stereo-divergence from a single oxirane substrate with easy access to both cis and trans carbamate isomers with high stereoselectivity ( $d r>19: 1)$. Key to control the diastereo-selective nature of the conversions leading to the trans carbamates is the in situ formation of trans-configured oligo/polycarbonates through Alcatalysis providing the targeted products after aminolysis. The present results demonstrate the valorization of a renewable carbon-based reagent $\left(\mathrm{CO}_{2}\right)$ into new valuable scaffolds and an unusual stereocontrol exerted through carbonate intermediates. A series of control experiments support the proposed mechanistic rationale towards the trans-carbamate products which is based on the trapping of an in situ formed trans-configured oligo/polycarbonate.
\end{abstract}

conditions when using simple alkylamines and mono-substituted COC reagents. ${ }^{[7]}$ The efficient aminolysis of di- and tri-substituted COCs has been seldom reported and should proceed with retention of configuration (Scheme 1). Cis-carbamates are produced straightforwardly from their respective cis-COCs derived from cyclic oxiranes and $\mathrm{CO}_{2}$ for which the synthetic methodology has advanced significantly over the years. ${ }^{[8]}$ However, the trans-carbamates cannot be easily accessed as there exists no general method for the formation of trans-COCs from cyclic oxirane precursors and $\mathrm{CO}_{2} \cdot{ }^{[9]}$

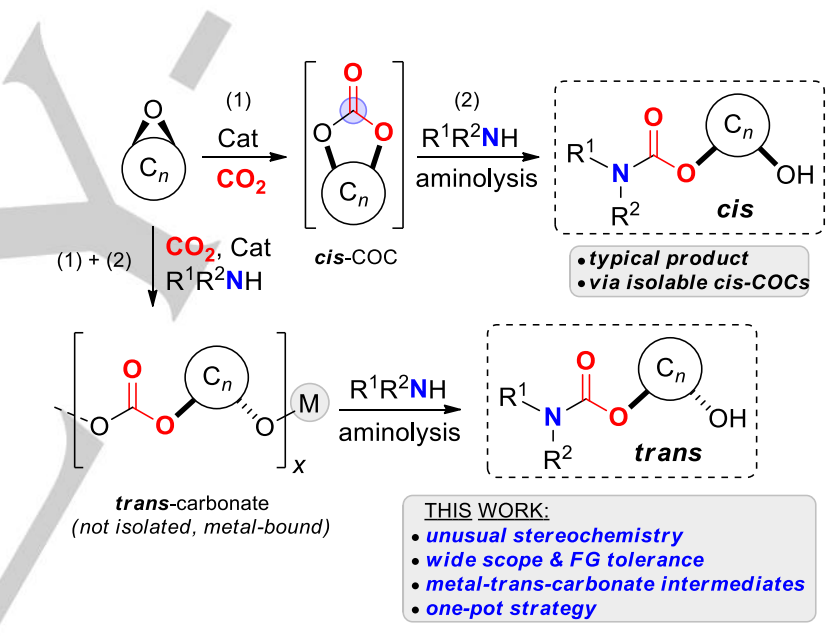

Scheme 1. Divergent approach towards carbamate synthesis using carbonate intermediates via a sequential $\left(1 \rightarrow 2\right.$; cis) or one-pot $\left(1+2\right.$; trans) approach. $C_{n}$ stands for a cycloalkyl skeleton with $n$ representing the number of $\mathrm{C}$-atoms.

In order to chase this synthetic challenge, we envisioned that in situ formation of a trans oligo/polycarbonate from cyclic oxiranes and $\mathrm{CO}_{2}$ could trigger the formation of a trans-carbamate by aminolysis. The use of appropriate catalytic copolymerization conditions would selectively lead to a growing trans-configured oligo-carbonate chain with subsequent aminolysis of the metalbound oligomer giving rise to trans-carbamates in a one-pot approach (Scheme 1). Here we report on a general, stereodivergent method for a wide range of functionalized carbamate structures derived from organic carbonate intermediates. Both the cis and trans diastereoisomers of these carbamate scaffolds can be formed with excellent stereo-control, with the family of unusual trans-configured products being generated through a conceptually new approach. 


\section{Results and Discussion}

As part of a screening study we first considered the one-pot conversion of cyclopentene oxides (cyclopentene oxide, CPO, and 3,4-epoxyfuran), three different primary amines $\mathrm{R}^{\prime}-\mathrm{NH}_{2}\left(\mathrm{R}^{\prime}=\right.$ $\mathrm{Cy}, \mathrm{Bu}, \mathrm{Oc}$ ) and $\mathrm{CO}_{2}$ using Al-catalysis (Table 1). ${ }^{[10]}$ Suitable nucleophilic additives, including $\mathrm{NBu}_{4} \mathrm{Br}(\mathrm{Br})$ and $\mathrm{PPNCl}(\mathbf{C l}$; PPN $=$ bis(triphenylphosphine)iminium) were used as these were previously shown to have the best potential in the formation of polymeric carbonates using aminotriphenolate complexes. ${ }^{[11]}$ It should be noted that cyclohexene oxide $(\mathrm{CHO})$ generally has excellent copolymerization potential, whereas cyclopentene oxides ( $\mathrm{Y}=\mathrm{C}$ or $\mathrm{O}$; Scheme to Table 1) are known to be more challenging substrates. Thus, we envisioned that successful in situ formation of oligomeric carbonates derived from cyclopentene oxides would serve better to validate a more general approach towards trans carbamates.

First, 3,4-epoxyfuran was investigated using both Al-catalysts $\mathbf{A}$ and $\mathbf{B}$ varying the co-catalyst nature and amount, and the amount of solvent (MEK; methylethyl ketone), see entries $1-11$ of Table 1. In the absence of Al-catalyst and nucleophile no conversion was noted (entry 1), while the use of complex $\mathbf{A}$ or nucleophile (TBAB) alone gave poor carbamate yields of $15 \%$ and $9 \%$, respectively (entries 2 and 3 ). Combination of both catalyst components gave more productive catalysis and afforded the desired carbamate product in much higher yields of up to $76 \%$ with excellent stereo-control ( $d r>99: 1$, entry 4). Additional variation of the amount of solvent, changing TBAB for $\mathrm{PPNCl}$ or using Al-complex $\mathbf{B}$ (entries 5-11) did not further improve these results, and at higher tem-peratures $\left(90^{\circ} \mathrm{C}\right.$, entry 10 versus 4$)$ loss of stereo-selectivity was noted.

In the case of cyclopentene oxide as substrate (entries 12-21), similar observations were done although in these reactions Alcomplex B combined with PPNCl provided the best compromise in terms of yield and diastereo-selectivity: the results reported in Table 1 show that the use of typical copolymerization conditions (i.e., using $\mathrm{Cl}$ as nucleophile, Al-catalyst $\left.\mathbf{B}, 60^{\circ} \mathrm{C}\right)^{[10,11]}$ leads to the preferred formation of the targeted trans-carbamate product with high dr's of up to $96: 4$ (entry 14) when $n$-octylamine is used, and $89: 11$ in the case of $n$-butylamine (entry 19). Again, in the absence of nucleophilic additive (as noted with 3,4-epoxyfuran), much lower yields of carbamate are noted (entries 16,17 and 20) likely to be the result of a relatively slow background reaction based on a carbamate nucleophile derived from the amine and $\mathrm{CO}_{2}$ (Figure 1). ${ }^{[12]}$ Longer reaction times do not seem to significantly affect the yield of carbamate (cf. entries 16 versus 17) under low-pressure conditions (10 bar).

We therefore tried the carbamate synthesis also under more severe pressure conditions ( 40 bar, entry 20 Table 1; cf. entry 21) and found only a small increase in the yield of the carbamate derived from CPO. This further confirms that for efficient formation of the trans-carbamate product under these relatively mild reaction conditions the presence of an external nucleophile is required, and offers the major pathway leading to transcarbamate product through in situ trans-carbonate formation.
Stands for nucleophile additive, Cy for cyclohexyl, Oc for $n$-octyl and Bu for $n$ butyl.

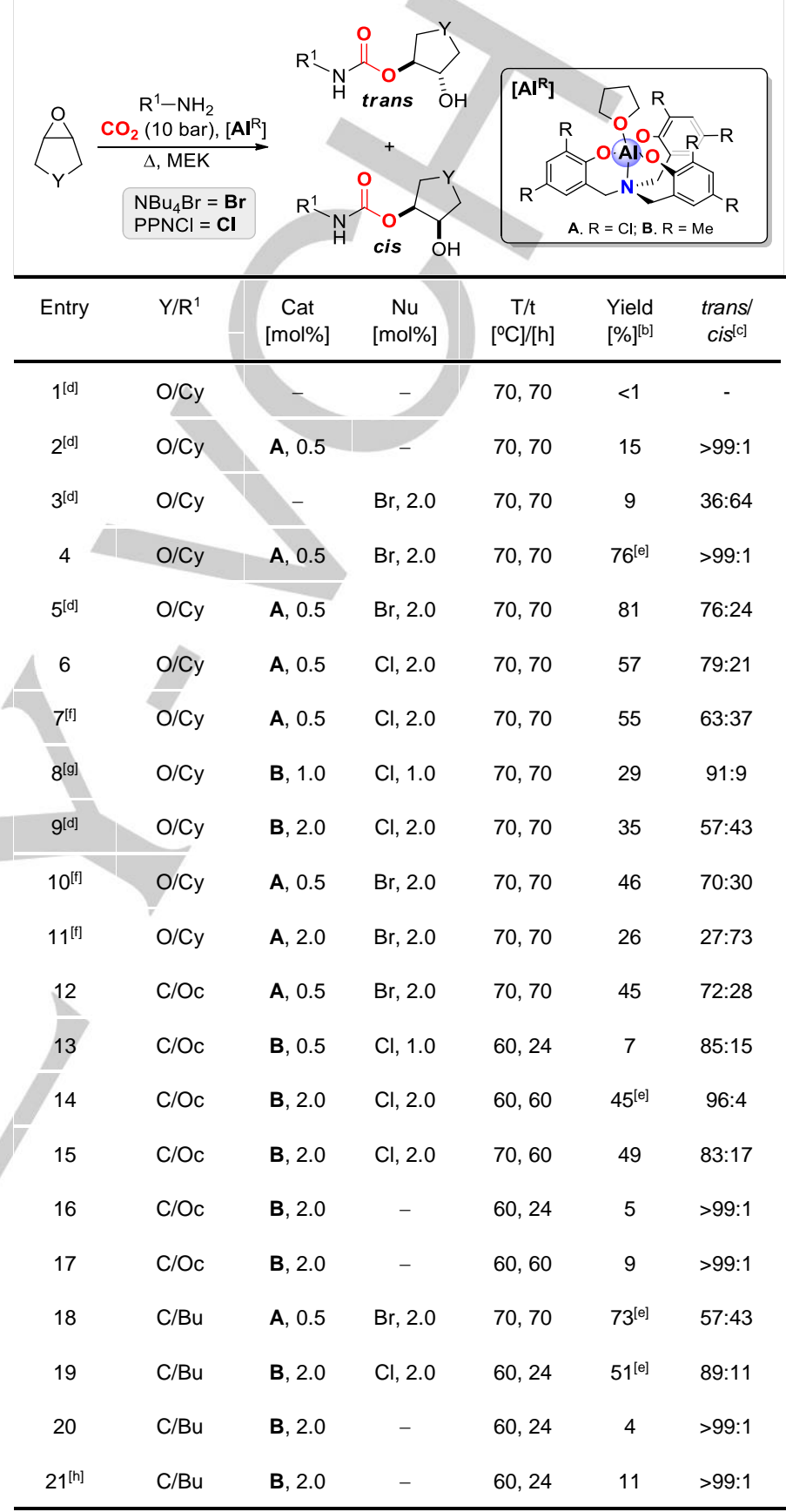

[a] Conditions: epoxide (4 mmol), $\mathrm{R}^{1}-\mathrm{NH}_{2}$ (1.2 equiv; $\mathrm{R}=\mathrm{Oc}$, $\mathrm{Cy}$ : 4 equiv.; $\mathrm{R}=$ $\mathrm{Bu}$ ) using $0.5 \mathrm{~mL}$ MEK (methylethyl ketone), $p\left(\mathrm{CO}_{2}\right)^{\circ}=10$ bar. ${ }^{\mathrm{b}]} \mathrm{NMR}$ yields using mesitylene as internal standard. ${ }^{[c]}$ Determined by ${ }^{1} \mathrm{H}$ NMR. ${ }^{[\mathrm{d}]}$ Using 1.0 $\mathrm{mL}$ of MEK. ${ }^{[e]}$ Isolated yields. ${ }^{[\mathrm{f}]}$ Using $2.0 \mathrm{~mL}$ of MEK. ${ }^{[\mathrm{g}]}$ Neat conditions. ${ }^{[\mathrm{h}]}$ Reaction carried out at 40 bar. 
Similar behavior in carbamate formation was also noted for one other cyclic and one acyclic epoxide when they were probed under similar temperature/pressure conditions (see Tables S1 and S2). In these latter cases good to excellent selectivity for the trans-carbamates ( $d r>99: 1)$ was noted validating further the current approach using an external nucleophilic additive.

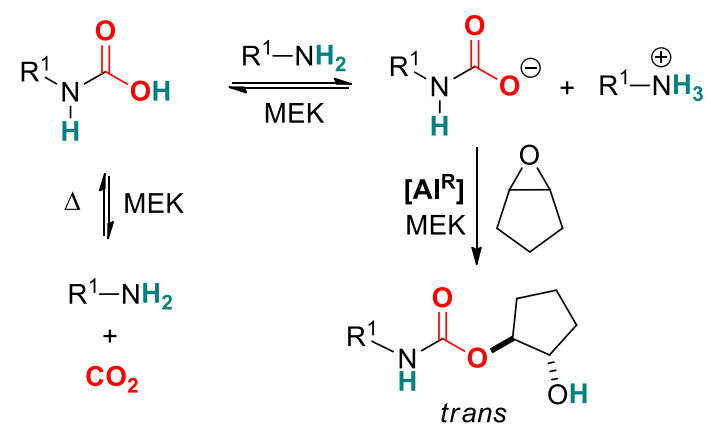

Figure 1. Potential background reaction to form a trans carbamate through the formation of a carbamate nucleophile from an amine and $\mathrm{CO}_{2}$.

Having established a set of suitable reaction conditions leading selectively to trans-configured carbamates, we then investigated the scope in more detail (1-15, see Figure 2). As reference materials for the assignment of the trans-products $\mathbf{1 b}-\mathbf{1 5 b}$, the cis-carbamates 1a-15a were separately prepared by prior formation of their cis cyclic carbonates derived from the respective epoxides under appropriate conditions. ${ }^{[6 d]}$ The aminolysis reaction was then carried out by addition of the appropriate amine and details are reported in the Supporting Information. In general, the stereo-control towards the transcarbamates $\mathbf{1 b} \mathbf{- 1 5} \mathbf{b}$ is excellent providing the compounds with $d r^{\prime}$ s of $\geq 93: 7$ (apart from $4 \mathbf{b}$ and 13b; $d r=89: 11$ and 77:23, respectively). The approach is applicable towards various fiveand six-membered cyclic and also acyclic epoxides (cis-2-butene oxide, cf. formation of $12 \mathrm{~b}$ and $13 \mathrm{~b}$ ) without compromising significantly the diastereo-selectivity of the reaction. Various functionalized amines are tolerated bearing allyl ( $2 b$ and $\mathbf{1 5 b}$ ), cyclopropyl (8b), thiophenelyl (9b), and pyridyl (11b) groups whereas the use of more functional epoxides allows for the incorporation of potentially useful furan $(3 b, 5 b, 7 b$ and $8 b$ ) or cyclohexenyl (2b and $\mathbf{1 4 b}$ ) fragments.

The molecular structures for carbamates 1-15 (both diastereoisomers) were fully supported by $1 \mathrm{D} / 2 \mathrm{D}$ NMR and IR spectroscopic techniques, and HRMS; for $\mathbf{5 a}$ and $\mathbf{5 b}$ the X-ray molecular structures (see Figure 3 and Supporting Information) ${ }^{[13]}$ were determined and further supported their cis and trans assignment in line with the spectroscopic data. The isolated yields for the cis-carbamates $1 \mathbf{a}-\mathbf{1 5} \mathbf{a}$ are generally higher than those obtained for the trans diastereo-iosmers 1b-15; this suggest that the one-pot approach with the amine present at the early stage of the reaction may, as expected, slow down overall kinetics as the amine may compete with epoxide coordination to the Al-center in complexes $\mathbf{A}$ or $\mathbf{B}$.

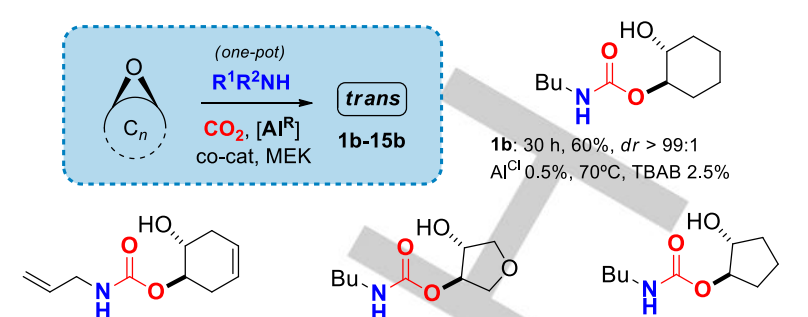

2b: 30 h, $54 \%, d r>99: 1$

3b: $60 \mathrm{~h}, 67 \%, d r>99: 1$

4b: $66 \mathrm{~h}, 51 \%, d r=89: 11$

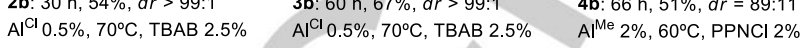<smiles>O=C(NCc1ccccc1)OC1CCCCC1O</smiles>

$\begin{array}{ll}\text { 5b: } 70 \mathrm{~h}, 76 \%, d r>99: 1 & \text { 6b: } 24 \mathrm{~h}, 72 \%, d r>99: 1 \\ \mathrm{Al}^{\mathrm{Cl}} 0.5 \%, 70^{\circ} \mathrm{C}, \mathrm{TBAB} 2.5 \% & \text { Al }^{\mathrm{Cl}} 0.5 \%, 70^{\circ} \mathrm{C}, \text { TBAB } 2.5 \%\end{array}$



7 b: $45 \mathrm{~h}, 65 \%, d r>99: 1$
Al ${ }^{\mathrm{Me}} 2 \%, 60^{\circ} \mathrm{C}, \mathrm{PPNCl} 3 \%$

$8 \mathbf{b}: 60 \mathrm{~h}, 50 \%, d r>99: 1$

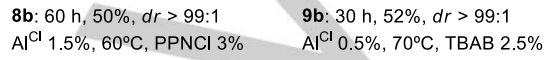

Octyl_

10b: $60 \mathrm{~h}, 45 \%, d r=96: 4$

10b: $60 \mathrm{~h}, 45 \%, d r=96: 4$
$\mathrm{Al}^{\mathrm{Me}} 2 \%, 60^{\circ} \mathrm{C}, \mathrm{PPNCl} 2 \%$

11b: $40 \mathrm{~h}, 43 \%, d r>99: 1 \quad$ 12b: $60 \mathrm{~h}, 56 \%, d r=93: 7$

$\overbrace{\mathrm{H}}^{\mathrm{N}} \mathrm{O}_{\mathrm{O}}^{\mathrm{O}} \mathrm{Me}$

13b: $30 \mathrm{~h}, 51 \%, d r=77: 23$

$\mathrm{Al}^{\mathrm{Me}} 2 \%, 60^{\circ} \mathrm{C}, \mathrm{PPNCl} 2 \% \quad \mathrm{Al}^{\mathrm{Cl}} 1.5 \%, 60^{\circ} \mathrm{C}, \mathrm{PPNCl} 3 \% \quad \mathrm{Al}^{\mathrm{Cl}} 1.5 \%, 70^{\circ} \mathrm{C}, \mathrm{PPNCl} 3 \%$

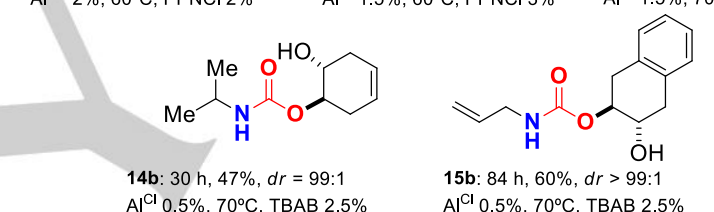

Figure 2. Scope for the formation of the trans-carbamates $\mathbf{1 b}-\mathbf{1 5 b}$. All reactions were carried out on a $4 \mathrm{mmol}$ scale using $0.5 \mathrm{~mL} \mathrm{MEK}, p\left(\mathrm{CO}_{2}\right)^{\circ}=10 \mathrm{bar}$, cat/cocat amounts are in $\mathrm{mol} \%$, and $\mathrm{Al}^{\mathrm{Cl}}=$ complex $\mathbf{A} ; \mathrm{Al}^{\mathrm{Me}}=$ complex $\mathbf{B}$. All $d r$ values were determined by ${ }^{1} \mathrm{H}$ NMR.
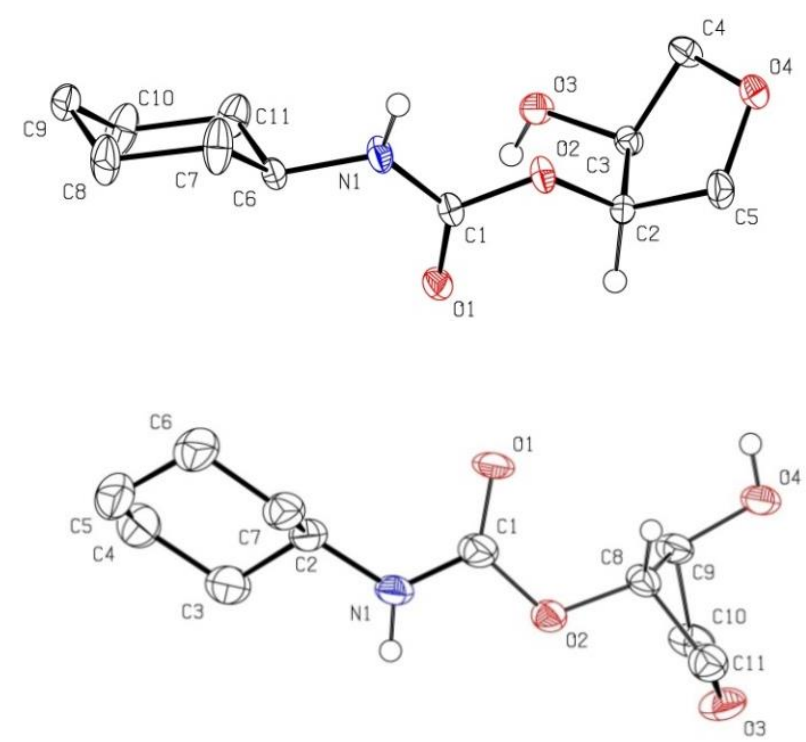

Figure 3. X-ray molecular structures determined for cis-5a (top) and trans-5b (below) together with part of the numbering scheme. 


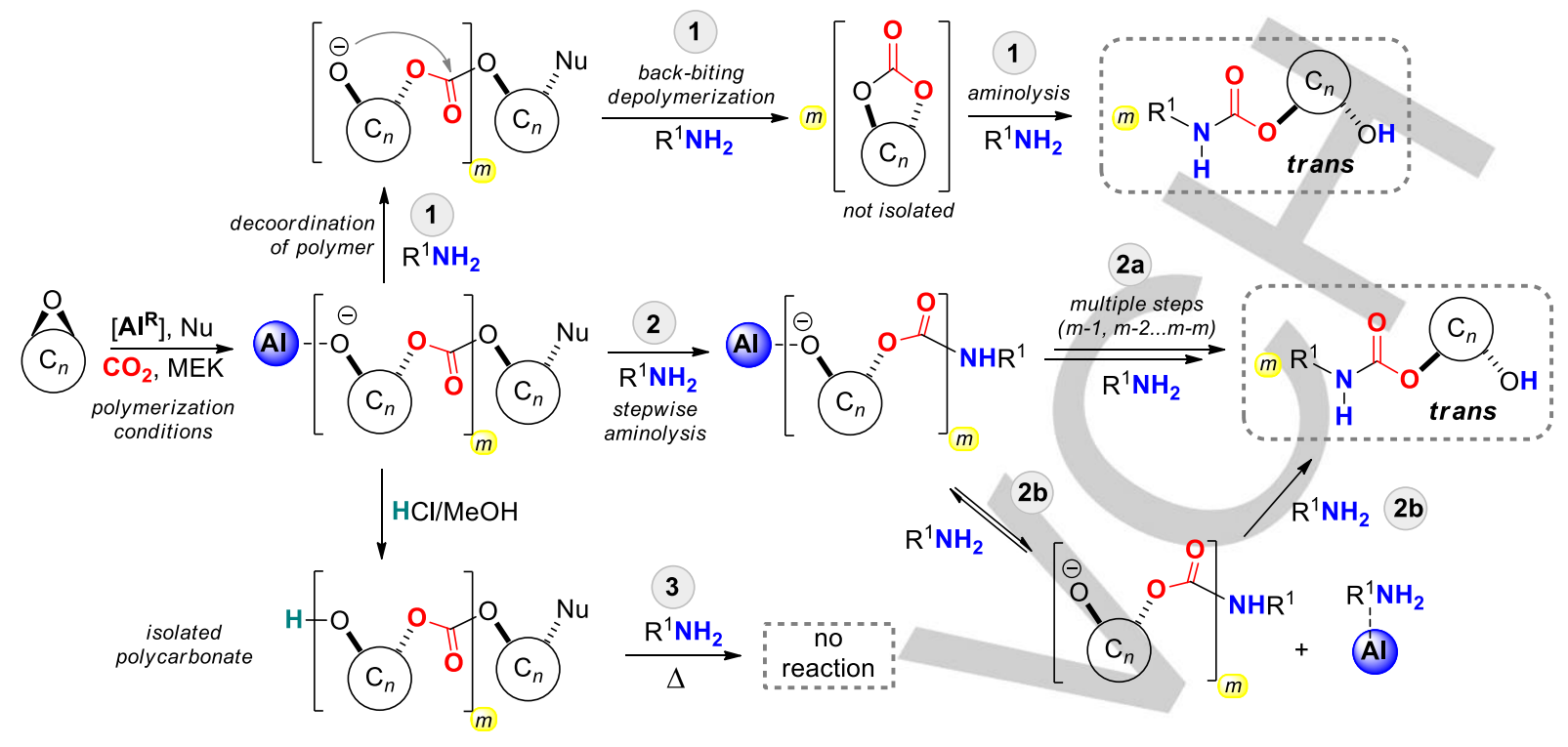

Scheme 2. Proposed mechanism for the formation of trans-carbamates through (1) formation of a trans-configured cyclic carbonate intermediate following aminolysis, or (2) a stepwise aminolysis of a metal-bound oligo/polycarbonate; pathway (3) shows the control experiment done with an isolated polycarbonate sample. The cation of the initial nucleophile is not shown here.

The isolated yields for the cis-carbamates $1 \mathrm{a}-15 \mathrm{a}$ are generally higher than those obtained for the trans diastereoiosmers 1b-15b; this suggest that the one-pot approach with the amine present at the early stage of the reaction may, as expected, slow down overall kinetics as the amine may compete with epoxide coordination to the Al-center in complexes A or $\mathbf{B}$. In order to investigate the mechanism of trans-carbamate formation, several additional experiments were conducted (see Scheme 2).

First, an isolated sample of a copolymer based on $\mathrm{CHO} / \mathrm{CO}_{2}$ (cf., path 3, Scheme 2) was subjected to the general reaction conditions of the one-pot carbamate formation (i.e., in the presence of $[\mathrm{Al}]$ complex $\mathrm{A}$, TBAB, MEK, $70^{\circ} \mathrm{C}, 18 \mathrm{~h}$ ) but the presence of the $n$-butyl amine did not provoke any observable aminolysis between $25-80^{\circ} \mathrm{C}$ as evidenced by ${ }^{1} \mathrm{H}$ NMR comparative studies (Supporting Information). Then we decided to freshly prepare the $\mathrm{CHO} / \mathrm{CO}_{2}$ copolymer in the absence of the amine using $\left[\mathrm{Al}^{\mathrm{Cl}}\right]$ catalyst $\mathbf{A}(0.5 \mathrm{~mol} \%)$ and TBAB $(2.5 \mathrm{~mol} \%)$ at $70^{\circ} \mathrm{C}$ for $24 \mathrm{~h}$; at this stage ${ }^{1} \mathrm{H}$ NMR analysis showed virtually full conversion into a fully alternating poly(cyclohexene)carbonate (PCHC, 99\% polymer selectivity) with trace amount (1\%) of transcyclohexene carbonate (trans-CHC). This copolymer (without applying the usual work up and with the metal likely still bound to the polymer) ${ }^{[14]}$ was treated with 3 equiv of $n$-butyl amine for $10 \mathrm{~h}$ at $70^{\circ} \mathrm{C}$ and then again analysed by ${ }^{1} \mathrm{H}$ NMR. Fortunately, conversion $(65 \%)$ to the carbamate $1 \mathrm{~b}(d r>99: 1)$ was noted with the remaining $35 \%$ consisting of a mixture of $85 \%$ PCHC and $15 \%$ of trans-CHC (i.e., a clear increase in the cyclic carbonate/polymer ratio is noted). The relative increase in trans$\mathrm{CHC}$ can be explained by a depolymerisation of the metal-free copolymer ${ }^{[15 e]}$ when adding the amine which may compete for coordination to the Al-center (Scheme 2, pathway 1). The decoordinated polymer then leads to trans- $\mathrm{CHC}$ by a relatively fast alkoxide back-biting process towards the trans-carbonate and in situ aminolysis to give trans-configured $\mathbf{1 b}$ as product.

A similar polymer degradation/aminolysis sequence (Scheme 2, pathway 1) seems plausible for the acyclic cis-2-butene oxide case. Control experiments were performed in the absence of amine reagent following the reaction conditions reported for $\mathbf{1 2 b}$ trans and 13b-trans (Figure 2). The ${ }^{1} \mathrm{H}$ NMR analysis showed the mixture to contain only the cyclic carbonate product with a trans selectivity of up to $83 \%$ which is in reasonable agreement with the reported $d r$ values for the two carbamate products derived from cis-2-butene oxide. Copolymers derived from cis-2-butene oxide have been reported recently by Darensbourg et al. ${ }^{[9 c]}$ showing that polymer-selective bifunctional $\mathrm{M}$ (salen) catalysts $(\mathrm{M}=\mathrm{Co}, \mathrm{Cr}$ ) give virtually only trans-carbonate upon alkoxide backbiting; this suggests that the trans-carbamates derived from cis-2-butene oxide also originate from pre-polymer formation.

However, the diastereoselective formation of transcarbamates using substrates such as CPO and 3,4-epoxyfuran cannot be explained via pathway 1 (Scheme 2). The group of Darensbourg has demonstrated that such a pathway is thermodynamically not feasible due to a high ring strain present in this trans cyclic carbonate, and therefore preferably results in degradation towards the starting epoxide and $\mathrm{CO}_{2}$. Under high pressure conditions, carbonate rather than alkoxide backbiting is facilitated resulting in exclusive cis-carbonate formation, ${ }^{[15]}$ excluding trans-carbamate formation through a trans cyclic carbonate intermediate.

We have recently shown by a combined experimental/computational approach that the coupling between limonene oxide (LO; Scheme 3 ) and $\mathrm{CO}_{2}$ gives exclusive 
formation of a fully alternating copolymer with a relative high barrier for (trans) cyclic carbonate formation. ${ }^{[10]}$ In this Almediated copolymerization process the $\mathrm{CO}_{2}$ insertion step was shown to be rate-limiting, suggesting that possible polymer degradation would have to proceed through alkoxide back-biting; both metal-bound and metal-free oligo/polycarbonates based on LO, however, are kinetically incompetent to give a trans cyclic carbonate via depolymerisation. This behaviour is reminiscent of copolymers derived from CPO which also cannot produce transCOC through alkoxide back-biting. Therefore, another degradation process (i.e., pathway 2 in Scheme 2) leading to formal trans-carbamate formation was considered.

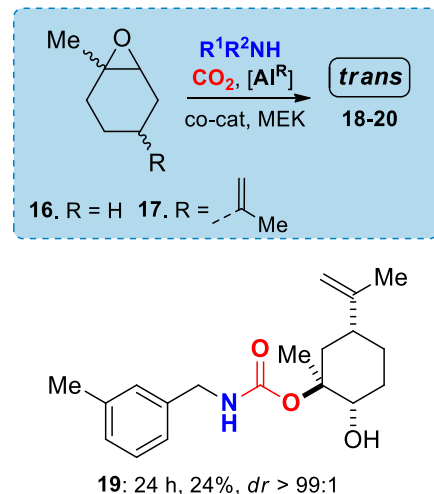

19: $24 \mathrm{~h}, 24 \%, d r>99: 1$ $\mathrm{Al}^{\mathrm{Me}} 2 \%, 60^{\circ} \mathrm{C}, \mathrm{PPNCl} 2 \%$

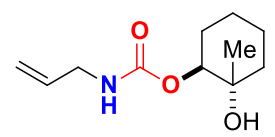

18b: $60 \mathrm{~h}, 39 \%, d r=99: 1$ $\mathrm{Al}^{\mathrm{Me}} 2 \%, 60^{\circ} \mathrm{C}, \mathrm{PPNCl} 2 \%$

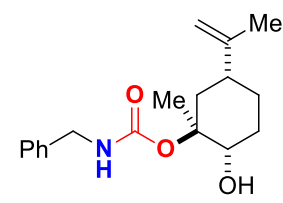

20: $24 \mathrm{~h}, 20 \%, d r>99: 1$ $\mathrm{Al}^{\mathrm{Me}} 2 \%, 60^{\circ} \mathrm{C}, \mathrm{PPNCl} 2 \%$
Scheme 3. Carbamate formation reactions using tri-substituted epoxides as reagents. Conditions: $4 \mathrm{mmol}$ scale, $0.5 \mathrm{~mL} \mathrm{MEK}, p\left(\mathrm{CO}_{2}\right)^{\circ}=10 \mathrm{bar}$, cat/co-cat amounts in mol\%. All $d r$ values were determined by ${ }^{1} \mathrm{H}$ NMR.

In order to investigate this in more detail, we envisioned that carbamate formation from tri-substituted cyclic oxiranes such as LO (Scheme 3) could serve to mimic the reactivity of CPO and related cyclic oxiranes. When we subjected both 16 (methylcyclohexene oxide) and 17 (cis-LO) to reaction conditions typically used for the formation of carbamates $\mathbf{1 b}-\mathbf{1 5 b}$, we only observed the formation of trans-carbamates 18-20. The origin of the trans-selectivity is ascribed to an attack of the amine on the oligo/polycarbonate itself being either metal-bound (pathway 2a) or metal-devoid (pathway $2 b$ ) through aminolysis at a carbonate linkage retaining thus the trans configuration in the final carbamate product. ${ }^{[16]}$

\section{Conclusions}

In summary, we here present an unprecedented catalytic approach towards trans-configured carbamates by selectively trapping of trans-carbonate intermediates with amine reagents. Supporting experiments have revealed that either in situ aminolysis of trans cyclic carbonates obtained through polycarbonate backbiting or aminolysis of in situ prepared transconfigured (metal-bound) oligo/polycarbonates is a new approach to exert a high degree of diastereo-selective control. Such a control is a new tool in the synthesis of $\mathrm{CO}_{2}$-derived fine chemicals showing potential in other types of synthetic transformations focusing on this renewable $C_{1}$ building block.

\section{Experimental Section}

\section{Typical procedure for the formation of the cis-carbamates}

The cyclic carbonates were first synthesized from carbon dioxide according to reported literature procedures ${ }^{[6 \mathrm{~d}, 17]}$ using $\mathrm{Al}(\mathrm{III})$ aminotriphenolate complex $\left[\mathrm{Al}^{\mathrm{Cl}}\right]$ as catalyst. After that, the respective carbonate ( $1 \mathrm{mmol}, 1$ eq.) and the corresponding amine (1.2 eq. for non-volatile amines; 4 eq. for volatile amines) were charged into a $5 \mathrm{~mL}$ round bottom flask and the reaction mixture was stirred at 50-70 ${ }^{\circ} \mathrm{C}$ for an appropriate time frame. After the reaction, the analytically pure carbamate product was isolated by flash chromatography. The Supporting Information contains all details regarding these cis-carbamates.

\section{Typical procedure for the formation of the trans-carbamates}

The respective epoxide ( $4 \mathrm{mmol}, 1$ eq.), Al-complex $\left(\mathrm{Al}^{\mathrm{R}}, 0.5-2.0 \% ; \mathrm{R}=\right.$ $\mathrm{Cl}$ or $\mathrm{Me}$ ), amine (1.2 eq. for non-volatile amines; 3 eq. for volatile amines), TBAB/PPNCl and MEK $(1 \mathrm{~mL})$ were charged into a $30 \mathrm{~mL}$ stainless steel autoclave. The autoclave was then subjected to three cycles of pressurization and depressurization with carbon dioxide ( $0.5 \mathrm{MPa}, 5$ bar), before final stabilization to a pressure of $1 \mathrm{MPa}$ (10 bar). The autoclave was sealed and heated to $60-90^{\circ} \mathrm{C}$ and left stirring for an appropriate time frame. Then, the autoclave was cooled to $\mathrm{rt}$ and carefully depressurized. The analytically pure carbamate product was then isolated by flash chromatography. The Supporting Information contains all details regarding these trans-carbamates.

\section{Acknowledgements}

We thank ICIQ, ICREA, and the Spanish Ministerio de Economía y Competitividad (MINECO) through projects CTQ-2014-60419$\mathrm{R}$, and the Severo Ochoa Excellence Accreditation 2014-2018 through project SEV-2013-0319. Dr. Noemí Cabello, Sofía Arnal, and Vanessa Martínez are acknowledged for the mass analyses. WG thanks the Cellex foundation for further financial support and VL acknowledges the Generalitat de Catalunya for a FI predoctoral fellowship.

Keywords: aluminium • carbamates $\cdot$ carbon dioxide $\bullet$ diastereoselective synthesis $\cdot$ organic carbonates

[1] a) Carbamates - Advances in Research and Application, Ed. Q. Ashton Acton, ScholarlyEditions, Atlanta - Georgia (USA), 2013; b) D. Chaturvedi, N. Mishra, V. Mishra, Curr. Org. Synth. 2007, 4, 308-320; c) E. Quaranta, M. Aresta in Carbon Dioxide as a Chemical Feedstock, Ed. M. Aresta, Wiley-VCH, Weinheim (Germany), 2010; d) P. Adams, F. A. Baron, Chem. Rev. 1965, 65, 567-602; e) O. Kreye, H. Mutlu, M. A. R. Meier, Green Chem. 2013, 15, 1431-1455. For a highly recent review on the use/synthesis of organic carbamates: f) A. K. Ghosh, M. Brindisi, J. Med. Chem. 2015, 58, 2895-2940.

[2] a) H.-W. Engels, H.-G. Pirkl, R. Albers, R. W. Albach, J. Krause, A. Hoffmann, H. Casselmann, J. Dormish, Angew. Chem. Int. Ed. 2013, 52, 
9422-9441; b) E. Delebecq, J. Pascault, B. Boutevin, F. Ganachaud, Chem. Rev. 2013, 113, 80-118

[3] See for example: a) D. Chaturvedi, Tetrahedron 2012, 68, 15-45 and references cited herein; b) R. L. Shriner, R. G. Child, J. Am. Chem. Soc 1952, 74, 549-550; c) H. Lebel, O. Leogane, Org. Lett. 2006, 8, 57175720 ; d) A. Porzelle, M. D. Woodrow, N. C. O. Tomkinson, Synlett 2009 798-802.

[4] a) C. Han, J. A. Porco, Jr, Org. Lett. 2007, 9, 1517-1520; b) M. Selva, P Tundo, A. Perosa, F. Dall'Acqua, J. Org. Chem. 2005, 70, 2771-2777; c) H. Zhou, F. Shi, X. Tian, Q. Zhang, Y. Deng, J. Mol. Cat. A: Chem. 2007 272, 89-92; d) M. Selva, P. Tundo, A. Perosa, Tetrahedron Lett. 2002 43, 1217-1219; e) I. Vauthey, F. Deâ, R. Valot, C. Gozzi, F. Fache, M. Lemaire, Tetrahedron Lett. 2000, 41, 6347-6350.

[5] a) L. Annunziata, A. K. Diallo, S. Fouquay, G. Michaud, F. Simon, J.-M. Brusson, J.-F. Carpentier, S. M. Guillaume, Green Chem. 2014, 16 1947-1956; b) M. Blain, L. Jean-Gérard, R. Auvergne, D. Benazet, S. Caillol, B. Andrioletti, Green Chem. 2014, 16, 4286-4291; c) H. Tomita, F. Sanda, T. Endo, J. Polym. Sci. Part A: Polym. Chem. 2000, 39, 860867; d) R. H. Lambeth, T. J. Henderson, Polymer 2013, 54, 5568-5573.

[6] For some recent reviews/contributions: a) C. Martín, G. Fiorani, A. W. Kleij, ACS Catal. 2015, 5, 1353-1370; b) J. W. Comerford, I. D. V. Ingram, M. North, X. Wu, Green Chem. 2015, 17, 1966-1987; c) S. Minakata, I. Sasaki, T. Ide, Angew. Chem. Int. Ed. 2010, 49, 1309-1311; d) V. Laserna, G. Fiorani, C. J. Whiteoak, E. Martin, E. Escudero-Adán, A. W. Kleij, Angew. Chem. Int. Ed. 2014, 53, 10416-10419; e) J. A. Kozak, J. Wu, X. Su, F. Simeon, A. Hatton, T. F. Jamison, J. Am. Chem. Soc. 2013 135, 18497-18501; f) Q.-W. Song, W.-Q. Chen, R. Ma, A. Yu, Q.-Y. Li, Y Chang, L.-N. He, ChemSusChem 2015, 8, 821-827; g) Y.-B. Wang, Y.M. Wang, W.-Z. Zhang, X.-B. Lu, J. Am. Chem. Soc. 2013, 135, 1199612003.

[7] Some recent examples: a) C. Hahn, H. Keul, M. Möller, Polym. Int. 2012 61, 1048-1060; b) S.-H. Pyo, P. Persson, M. A. Mollaahmad, K. Sörensen, S. Lundmark, R. Hatti-Kau, Pure Appl. Chem. 2012, 84, 637661 ; c) S. Benyahya, M. Desroches, R. Auvergne, S. Carlotti, S. Caillol, B. Boutevin, Polym. Chem. 2011, 2, 2661-2667; d) M. Helou, J.-F. Carpentier, S. M. Guillaume, Green Chem. 2011, 13, 266-271. See also reference $5 b$.

[8] a) J. Martínez, J. A. Castro-Osma, A. Earlam, C. Alonso-Moreno, A. Otero, A. Lara-Sánchez, M. North, A. Rodríguez-Diéguez, Chem. Eur. J. 2015, 21, 9850-9862; b) C. J. Whiteoak, N. Kielland, V. Laserna, E. C Escudero-Adán, E. Martin, A. W. Kleij, J. Am. Chem. Soc. 2013, 135, 1228-1231; c) C. J. Whiteoak, E. Martin, M. Martínez Belmonte, J. BenetBuchholz, A. W. Kleij, Adv. Synth. Catal. 2012, 354, 469-476; d) C. Beattie, M. North, P. Villuendas, C. Young, J. Org. Chem. 2013, 78, 419426.

[9] Only a few contributions report the formation of trace or very low amounts of trans-COCs from the depolymerisation of poly(carbonate) precursors these COCs were neither isolated nor used in further synthesis. See: a) A. Buchard, M. R. Kember, K. G. Sandeman, C. K. Williams, Chem.
Commun. 2011, 47, 212-214; b) D. J. Darensbourg, P. Bottarelli, J. R. Andreatta, Macromolecules 2007, 40, 7727-7729; c) D. J. Darensbourg, W.-C. Chung, Macromolecules 2014, 47, 4943-4948; The selective formation of a trans-carbonate from cis-2-butene oxide was also reported recently: d) C. J. Whiteoak, E. Martin, E. C. Escudero-Adán, A. W. Kleij, Adv. Synth. Catal. 2013, 355, 2233-2239.

[10] $\mathrm{Al}$ (aminotriphenolate) complexes are effective epoxide/ $\mathrm{CO}_{2}$ copolymerization catalysts, see: L. Peña Carrodeguas, J. GonzálezFabra, F. Castro-Gómez, C. Bo, A. W. Kleij, Chem. Eur. J. 2015, 21, 6115-6122.

[11] For $\mathrm{Fe}$ (III) based aminotriphenolates a selective switch in chemoselectivity between the cyclic and polycarbonate was observed in cyclohexene oxide/ $\mathrm{CO}_{2}$ couplings, see: $\mathrm{M}$. Taherimehr, S. M. Al-Amsyar, C. J. Whiteoak, A. W. Kleij, P. P. Pescarmona, Green Chem. 2013, 15, 3083-3090.

[12] Under the reaction conditions, the amine may react with $\mathrm{CO}_{2}$ to form a carbamate species which can ring-open the epoxide to form the transcarbamate albeit in very low yield. Thus, this is a much slower reaction than the ones studied here with added nucleophiles. This background reaction proceeds somewhat better under much harsher pressure conditions (i.e., 50 bar) with concomitant formation of substantial aminoalcohol side-product, see: F. Kojima, T. Aida, S. Inoue, J. Am. Chem. Soc. 1986, 108, 391-395. Apparently, under the mild conditions reported here the formation of a carbamate nucleophile derived from the amine and $\mathrm{CO}_{2}$ is either catalytically incompetent or only formed in very low concentration. The use of secondary amine reagents leads only to amino alcohol formation, i.e. aminolysis of the oxirane substrate occurs.

[13] For more details: CCDC-1039414 and CCDC-1423217.

[14] For living copolymerisation see: J. G. Kim, C. D. Cowman, A. M. LaPointe, U. Wiesner, G. W. Coates, Macromolecules 2011, 44, 1110-1113.

[15] a) D J. Darensbourg, A. D. Yeung, Macromolecules 2013, 46, 83-95; b) D. J. Darensbourg, A. D. Yeung, S.-H. Wei, Green Chem. 2013, 15, 1578-1583; c) D. J. Darensbourg, S.-H. Wei, A. D. Yeung, W. Chadwick Ellis, Macromolecules 2013, 46, 5850-5855. See also: d) D. J. Darensbourg, A. D. Yeung, Polymer Chem. 2014, 5, 3949-3962; e) D. J. Darensbourg, A. D. Yeung, Polymer Chem. 2015, 6, 1103-1117.

[16] Note that the regio-selectivity for the formation of $\mathbf{1 8 b}$ is different from the ones observed for trans $\mathbf{1 9}$ and $\mathbf{2 0}$. This is likely a function of the amine reagent as the formation of other carbamates from methylcyclohexene oxides using $p$-methoxy-benzylamine under similar reaction conditions was shown to give a regio-isomeric mixture (combined yield $32 \%$; regio-selectivity 58:42). See for full details the Supporting Information.

[17] C. J. Whiteoak, N. Kielland, V. Laserna, F. Castro-Gómez, E. Martin, E. C. Escudero-Adán, C. Bo, A. W. Kleij, Chem. Eur. J. 2014, 20, 2264 2275. 


\section{Entry for the Table of Contents:}

\section{FULL PAPER}

Cuts both ways: Stereodivergence in carbamate synthesis has been achieved through a selective trapping of carbonate intermediates under Alcatalysis using cyclic oxiranes, amines and $\mathrm{CO}_{2}$ as reaction partners. Both trans and cis carbamates were produced with $d r$ values $>19: 1$.

Mechanistic investigations support the view of a key transconfigured oligo/polycarbonate intermediate controlling the stereo-selectivity in this conceptually new catalytic $\mathrm{CO}_{2}$ conversion approach.

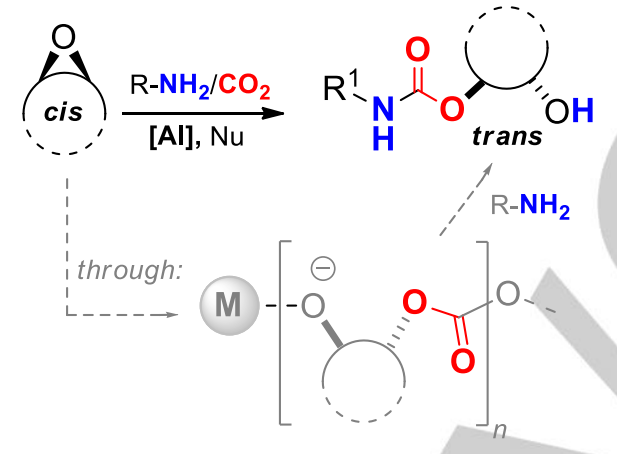

- Operationally simple, under mild Al-catalysis - $d r>19: 1$, isolated yield up to $82 \%$

- 18 examples based on (a)cyclic oxiranes

- In situ trapping of trans-carbonate intermediate
Wusheng Guo, Victor Laserna, Eddy Martin, Eduardo C. Escudero-Adán and Arjan W. Kleij ${ }^{*}$

Page No. - Page No.
Stereodivergent Carbamate Synthesis by Selective In Situ Trapping of Organic Carbonate Intermediates 